\title{
Crime Prevention in Urban Spaces through Environmental Design: A Critical UK Perspective
}

\author{
Abstract \\ Crime Prevention through Environmental Design (CPTED) and the Defensible Space Theory have \\ been adopted to enable the effective use of the built environment to reduce crime. The occurrence \\ of crime is widely accepted to be context-specific. Some explanatory theories have focused on social \\ disorder, alluding to the notion that if such disorders are eliminated from society then serious crime \\ would be eradicated. Numerous approaches have considered the use of environmental design and \\ spatial configuration as a possible solution to reduce crime. The main aim of this study is to gain \\ further understanding of stakeholders' perceptions of Brixton Town Centre (BTC) in London and thus \\ advance the discourse of CPTED. Using a mixed methodology approach, a visual audit of CPTED, a \\ critical analysis of police crime data, questionnaire surveys and semi-structured interviews were \\ carried out to gauge the effectiveness of key CPTED intervention principles identified in BTC. It was \\ revealed that since the interventionary measures began in BTC in 2011, there has been an increase \\ in the crime rates for other parts of England and Wales whilst BTC in particular has experienced a \\ decline. A positive correlation was found between length of residency in the area and fear of crime. \\ Lighting was critical to people's perception of feeling secure. Finally, the research findings revealed \\ that although crime rates had fallen in BTC, stakeholders agree that further improvement was \\ required. This research concludes with a proposal of further study that will theorize the \\ phenomenon occurring at BTC.
}

Keywords: Brixton; CPTED; Crime prevention; Crime rates; Defensible Space Theory. 


\section{Introduction}

One of the solutions to enhance safety in urban spaces is to increase their all-inclusiveness. Allinclusiveness in urban space means creating equal and wider opportunities for participation of all parties to keep the public space lively and safe (Farr and Piroozfar 2013). Modern criminology on the other hand seeks to address safety in urban spaces by explaining causes and impacts of crime to help control offenders and prevent crime (Fink 1938) and acknowledges that rarely do criminal acts have single causes. The theories of crime prevention are classified using different methodologies, causes and categories of their source or impact. One of such classifications advocates for the idea of a relationship between the crime and its context; more specifically the urban environment (Jeffery and Zahm 1993). This started with works of Elizabeth Wood and Jane Jacobs in 1960 and was developed further into a new dimension with Kelling and Wilson's 'Broken Windows Theory'. This subsequently evolved when the sociologist and criminologist C. Ray Jeffery first coined the term Crime Prevention Through Environmental Design (CPTED) in the 1970s. This concept also shares many principles with Oscar Newman's 'Defensible Space Theory' (Newman 1972, Newman 1996, Shjarback 2014). The Defensible Space Theory was inspired by the mass demolition of Pruitt-lgoe housing complex in city of St. Louis, Missouri on 16 March 1972 (Allen and Wendl 2014); what was declared as "the day Modern Architecture died" by Charles Jencks. Designing to prevent crime is a concept that has evolved considerably over time and also is context-specific as many factors need to be considered when making such crucial decisions (Crawford and Evans 2017). Following on from the premise of phasing out crime using environmental design, this research critically evaluates approaches to crime prevention through design using a specific geographical location and its transformation over recent decades.

The theory of CPTED i.e. strategically focusing on design to enable the effective use of the built environment to reduce criminal activity and aid in the reduction of fear of crime, is used in this study to investigate how crime can be reduced in urban spaces, using the case of Brixton Town Centre (BTC) in South West London, UK. This research reviews principles of CPTED, namely territoriality, surveillance, access control, activity support, image management, and target hardening within geographical juxtaposition (figure 1) to find out if and how they have aided in the reduction of criminal activity and fear of crime after some urban design interventions were introduced in the town centre which is known to have a history of violence in South West London, UK. The results of the research show a reduction of

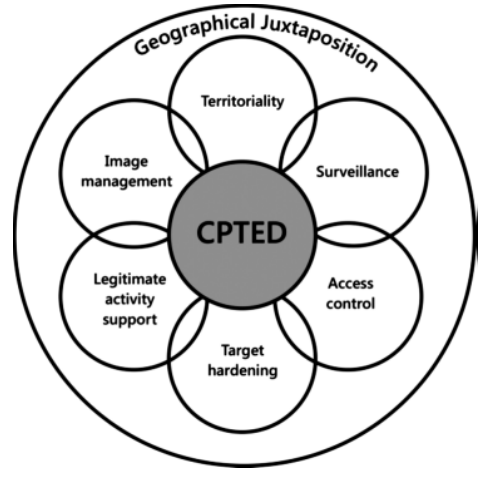

Figure 1 - The seven principles of CPTED (Cozens and Love 2015) crime in the town centre after CPTED interventions had been implemented. This study focuses solely on crime and crime prevention in the area and excludes the concept of gentrification.

\section{Setting the scene: the path to modern criminology ${ }^{1}$}

Crimes are committed for many reasons and similarly, fear of crime is developed for various reasons. Stemmed from sociology and not mutually exclusive from it, modern criminology is known to have evolved into several schools of thought: classical, positivist and post-positivist criminology; each of which comprises several theories. Those theories have their own strengths and weaknesses

\footnotetext{
${ }^{1}$ This section has been developed based on free reading of several seminal texts in criminology including but not limited to: Siegel, L. J. (2011). Criminology : the core. Belmont, CA, Wadsworth/Cengage Learning, ibid., ibid., School of Education (2016). Theories and causes of crime, The Scottish Centre of Crime and Justice Research, School of Education, University of Glasgow, Siegel, L. J. (2016). Criminology: theories, patterns, and typologies. Belmont, CA, Wadsworth Cengage Learning.
} 
corroborating that there is no absolute right or wrong in criminology and different theories seek to explain the causes of crime from different angles (Garofalo 1981). Hagan and Daigle (2018) share the same views on the origins and evolution of the concept of criminology and add that there are numerous definitions of what constitute as criminal activities. The classical criminology, which advocates capital punishment as a form of deterrent and retribution, suggests that criminals make a rational choice when committing crime and in order to control it, it is crucial that the punishment outweighs the benefits of the offence. It takes a reactionary (as opposed to preventative) stand linking crime directly to punishment - and almost only with punishment. This has led the concept to be widely criticized. Moreover, it has been criticized for failing to acknowledge the role and impact of many other factors in committing crimes such as culture, gender, age, education and social engagement - whether these are short, mid or long-term effects. Despite classical criminology being criticized for not reinstating a sense of morality or for the punishment having little to no rehabilitation effects as they were originally intended, the Right Realists seem to have come back to advocate it in favour of informing criminal justice policy. This has given rise to Rational Choice Theory (Cornish and Clarke 1986). They have serious critiques between Left Realists, who, to the contrary, build upon Relative Deprivation Theory ${ }^{2}$ principles to argue that crime disproportionately affects the lives of the poor and disadvantaged (Lea and Young 1984, Currie 1985), hence punishment, especially if it is raised disproportionately, drives the society down the spiral of a vicious circle of reproduction of crime.

Biological theories, which probably started with C19 ${ }^{\text {th }}$ Lombroso's 'atavistic' view of criminals, even in their rather contemporary sense are heavily weighted towards positivism, hence prone to be easily criticized for their lack of proactive account of sociological, psychological or organizational constructs influencing crime, and informing criminology theories. Pure modern criminology theories, by contrast, tend to build their arguments on or around sociology, psychology or behavioural sciences with a post-positivist - constructivist, pragmatist or advocacy - approach at their core. Merton (1957) builds upon Durkheim's Anomie to form Strain Theory and argues that the sheer gap between the societal goals and the means of achieving them may cause exasperation or antipathy and result in illegal activities to achieve those goals. This however is not necessarily always the case and criticism of Social Strain Theory varies widely from lack of criticism of the social structure to lack of empirical evidence; and from its limited application to certain social classes or social groups to its lack of gender inequality or failure of inter- vs. intra-personal aspects of crime (Kornhauser 1978, Bernard 1984). Some such as Cloward and Ohlin (1960) have sought to respond to some of shortfalls of Strain Theory with regards to its lack of criticism of the social structure. They base their argument on Cohen's Subcultural Theory (1955) - which is again rooted in Durkheim's Anomie and related to Strain Theory but with a slightly different socio-culture emphasis - to argue that tendency to create their own subcultural system of values between lower-class youths, who could not aspire to middleclass cultural goals, may end up in different 'opportunity structures' such as crime, fight, violence or drug abuse. From a slightly different angle Hirschi's Social Control Theory (1969) sought to establish why people obey the law. Social Strain Theory, together with Social Disorganization, Social Ecology, Institutional Anomie, Subcultural and Control Theories form the most important Social Structure Theories in criminology within the post-positivist school of thought. However, only a limited number of post-positivist theories have a focus on place or space, or are related to them; what is intended in this study.

\footnotetext{
${ }^{2}$ Although Relative Deprivation Theory argues that regardless of being poor or rich, the perception of being relatively deprived may result in criminal behaviour and subsequently in morally questionable decisions.
} 
Literature Review

\section{Place-based Crime Prevention}

Spatial mapping dates back to the first half of $\mathrm{C}_{2} \mathrm{O}^{\text {th }}$ as a basis for what is known as Social Disorganization Theory (Shaw and McKay 1942). It also forms the foundation for place-based crime and crime prevention theories which rose due to the fact that crime was found to be concentrated in particular areas of the city, and remains relatively stable within different areas despite incessant changes in the population and the demography of inhabitants in those area. Modern crime theories which associate crime with space and/or place include defensible space theory, broken windows theory, and routine activities theory. These form the main underpinning theory on which this study has been built.

Urban theorists and researchers have suggested that city planners and urban designers should develop a systematic feedback loop to transfer the learning experience of the public space from the post-occupancy and operational stages into planning and design stages to increase the allinclusiveness of the public space which in return adds to safety and livelihood of the space (Farr and Piroozfar 2013). Wood's security guidelines for the Chicago Housing Authority in 1961 together with Jacobs' indictment of new urban architecture, which suggested "[modern] cities were custom-made for crime" (Jacobs 1961) and led to her theory of 'eyes on the street', reinforced the need for natural surveillance and territoriality. They both laid the foundation for some of the main theories for placebased crime prevention theories such as Broken Windows theory, CPTED, Defensible Space and the theoretical basis for Space Syntax. Place-based crime prevention is a methodology that addresses the relationship between a physical environment and the occurrence of crime; more often than not independently of the population and the demographic construct of inhabitants or users of the place or space in question. It is a multi-disciplinary approach to the reduction of crime and an increase of the perceived safety. It focuses on the built environment and how spaces are used and how they can be manipulated to best reduce incidents of crime (Moore 2000). Directly informed or indirectly inspired by the theoretical foundations of place-based crime prevention, some pragmatic solutions such as, but not limited to, the UK-based Secured by Design ${ }^{3}$ have been developed to help improve security of buildings and cut the crime rate, criminal activities and antisocial behavior around buildings. Although some academic research and statistics have been provided, it seems more evidence is still required to support effectiveness of such measures.

\section{Crime Prevention through Environmental Design (CPTED): Existing Theories}

First coined by the C. Ray Jeffery in the 1970s, CPTED suggests that the physical environment can provide opportunities for crime to occur. Thus indicating that crime can be reduced by varying environmental factors. The aim of CPTED is to alter the physical environment to ensure that the 'normal' users feel safe, but making the 'abnormal' users feel uneasy and apprehensive about engaging in any inappropriate anti-social behaviour (Dorn 2005). Jeffery (1971) argued that social causes of crime such as subcultural influences and relative deprivation have been over-elaborated by sociologists and that more focus was needed on reduction of environmental opportunities for crime (Cornish and Clarke 2002). CPTED is moderately criticized for having a deterrent rather than a preventative effect. Advocating CPTED, Jeffery (1971) acknowledges the importance of the psychological and biological alongside environmental factors in crime (see also Parnaby 2006). Another broad critique about CPTED is its associated costs in retrofit or regeneration projects. However, there is limited research to academically substantiate this claim and it is equally argued that, considering the direct and indirect costs of crime, CPTED is probably among the most cost-

\footnotetext{
${ }^{3}$ A police initiative created in 1989 to improve the security of buildings and their immediate surroundings to provide safe places to live, work, shop and visit (see: https://www.securedbydesign.com/ for more details).
} 
effective crime prevention measures. It reduces the overall costs of preventing crime when it is factored in during the early stages of design and engaging all stakeholders and especially communities and space-user groups. More research to investigate crime life-cycle cost and effect is required; this would need an especially tailored research design and methodology.

\section{Broken Windows Theory}

Kelling and Wilson's 'Broken Windows Theory' (1982) suggests that the physical environment plays a crucial role in the rate of criminal activity and fear of crime. Suggesting that law enforcement only focused on the serious crime, Kelling and Wilson believed that the serious crimes occurred as a result of a series of minor crimes that led to a final serious crime (Cozens 2008). Their theory was that crime emulated from disorder, and if disorder was eliminated then serious crime would not occur. A particular criticism against the theory has been the link between 'undesirables' such as the homeless and crime. However, this link has been shown by other researchers to be often nonexistent (Harcourt 2001). The theory has also been criticized for being only a short-term partial solution (Taylor 2001), criminalization of communities of colour (Roberts 1999), implicit bias against racial or cultural minorities (Sampson and Raudenbush 2004), building up on the premise that social disorder and crime are assumed to have a causal-effect relation, failing to take into account a third factor, i.e. collective efficacy (Sampson and Raudenbush 2004) and more broadly for not being theoretically robust enough (Thacher 2004). Nevertheless, the Broken Windows Theory has heavily contributed to the place-based crime prevention theories by arguing that a well-maintained environment could reduce and prevent criminal activities. The theory also reinforced the principles of natural surveillance and territoriality, which became some of the core principles of place-based crime prevention theories.

\section{Defensible Space Theory}

The Theory of the Rational Offender, shifted the focus from the thoughts and behaviour of the offender to the physical environment and on the offender's decision trees and how it is influenced by the environmental factors, known as "cues". It formed the basis for the Defensible Space Theory which was developed in early 1970s by Oscar Newman based on seven main concepts ${ }^{4}$. It encourages the use of design in order to enhance territoriality and to create a sense of ownership by clearly differentiating between private and public spaces using symbolic barriers (figure 2). It was further developed

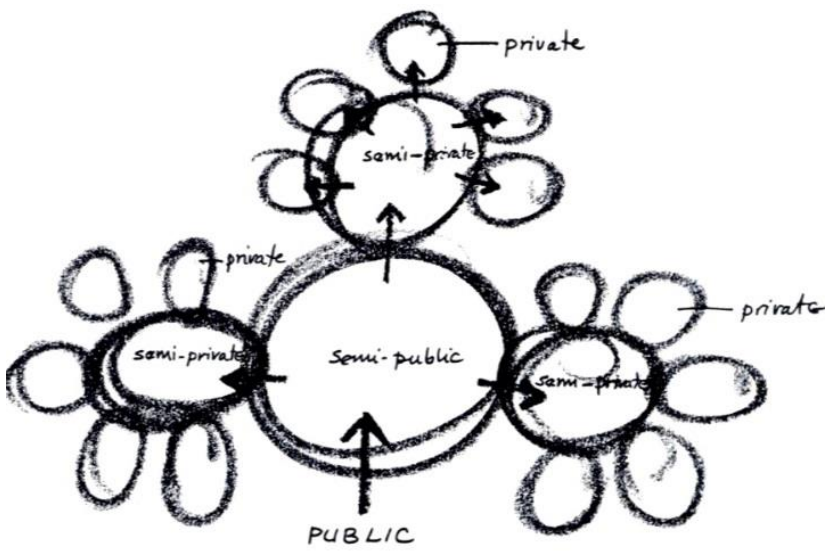

Figure 2 - Discreet defensible spaces allocated to various residents (Newman 1996) into what was claimed to be 'the $2^{\text {nd }}$ generation CPTED', where its implications were attempted to be expanded by Saville and Cleveland (1997) who drew attention to some urban design (and planning) features with an emphasis on crime prevention; namely human scale development, urban meeting places, youth clubs, residents' participation and residents' responsibility. The development expanded on some of already existing features (e.g. image and access control) and included two new aspects: influence of surrounding

\footnotetext{
${ }^{4}$ Four of those concepts were initially developed by Newman with new developments added either by him or the others in the next 40 years or so. Those are: territoriality, surveillance, access control, boundary definition, activity support, image management and, target hardening.
} 
activities and, the use of adjoining lands (Saville and Cleveland 1997), suggesting that concepts such as natural surveillance and territoriality need to be more inclusively considered in order for good designs to be created (Parnaby 2006). The Defensible Space Theory also focuses on design standards that can improve architecture, land use, security and lighting, and places significant emphasis on territoriality and the need for residents to gain a sense of ownership; which is needed in order for the design to be effective (Robinson 1996). The Theory puts the blame on the design and layout of 'public housing' and criticizes the inhuman large scale of the developments, their location in neighborhoods with high crime rates, their stark design that make them seem as if no one cares about them, and the inability for residents to get to know each other because the large buildings make it hard to identify intruders (Cornish and Clarke 2002). Suggestions therefore, are made to encourage territorial behaviour of residents whose presence could provide surveillance around their residences and advocate the construction of boundaries that reinforce natural territoriality to help residents intervene and prevent crime in their spaces (Knoblauch 2015).

Table 1 lists the connections between defensible space and CPTED. Both concepts focus on using borders and boundaries to ensure there are safe spaces for users with regard to crime prevention.

Table 1: Connections between defensible space and CPTED (Schneider and Kitchen, 2002: 102,

$$
\text { in: Cozens, 2008: 160) }
$$

\begin{tabular}{ll}
\hline \multicolumn{1}{c}{ Defensible Space } & \multicolumn{1}{c}{ CPTED } \\
\hline Territoriality and boundary definition & Border definition of controlled space \\
Territoriality, boundary definition and access control & Clearly marked transitional zones \\
Surveillance and access control & Attention directed to gathering areas \\
Image ad milieu and geographical juxtaposition & Place safe activities in unsafe areas \\
Image and milieu and geographical juxtaposition & Place unsafe activities in safe areas \\
Boundary definition and success control & Reduce use conflicts with natural barriers \\
Geographical juxtaposition & Better scheduling of space \\
Surveillance & Increased perception of natural surveillance in spaces by design \\
Geographical juxtaposition & Overcome distant an isolation by communication \\
\hline
\end{tabular}

\section{Research Design and Methodology}

This research utilizes a mixed methodology as it seeks to gain insight and an understanding into people's perceptions of environmental design aspects and their impacts on crime and crime prevention in addition to objective and quantifiable counts such as crime statistics. Complimentary methods are utilized to achieve the research aim. The Brixton Town Centre (BTC), which has been subject to a regeneration programme, has been used to investigate CPTED and crime prevention strategies.

Case study research is used to contribute to the knowledge of the researcher and reader which can be of a specific group, organization or social environment (Yin 2014). The case study design that has been chosen for this research is the embedded single-unit case study (Yin 2014), which requires collection of different datasets, information and facts, and a cross-analysis of the relationships between them. The evaluation of the BTC case study will involve data collection using a number of different techniques, which has been described in depth next, hence the proposed mixed methodology approach. This is deemed the most appropriate approach as the research seeks to gain insight and an understanding into people's perceptions of the environment of BTC.

To fulfil the aim of this research, age, gender and length of residency were quantified and used as a basis for the quantitative survey to test people's perception of safety in BTC. Accordingly, three hypotheses were formulated as follows:

$\mathrm{H}_{1} 1$ : Female users will feel safer in the area after dark 
$\mathrm{H}_{1}$ 2: Teenager users will feel less safe in the area after dark

$\mathrm{H}_{1} 3$ : Residents with a residency over 10 years will feel safer in the area after dark

And their corresponding null hypothesis were tested:

$\mathrm{H}_{0} 1$ : Female users will not feel safer in the area after dark

$\mathrm{H}_{0}$ 2: Teenager users will not feel the least safe in the area after dark

$\mathrm{H}_{0} 3$ : Residents with a residency over 10 years will not feel safer in the area after dark

A chi-square test was conducted for gender, age and length of residency against 'how safe they felt in the area after dark'.

Following completion of the survey and building upon the finding of it in combination with what was found through the literature review stage, the secondary research and findings of the visual audit of the CPTED carried out in BTC, an in-depth interview was designed to gain more detailed insight of how people perceived the environmental design measures and their impacts on crime prevention under the following themes:

1. Crime that affected business (drugs and alcohol related and general theft);

2. Initial fear of working in Brixton;

3. Preventive measures (implemented CCTV, signage and security);

4. Interventions (which have had positive effect on criminal activity);

5. Changes of public space (which have created new exciting spaces for the community, passers-by and tourist);

6. Increase in police presence;

7. Areas which are still deemed challenging in terms of criminal activity;

8. Displacement of criminal activity to other areas in the town.

The following research methods and techniques were adopted to collect data for both quantitative and qualitative compartments of this research:

\section{Police crime data}

To determine whether the CPTED interventions had been effective, one objective of this research was to investigate the levels of crime rates pre- and post-intervention. In order to receive the police data, a Freedom of Information request (FOI) was carried out for the years pre- and postintervention. Between 2001 and 2014, the crime data for antisocial behaviour, drug related violence and sexual offences, theft from a person, criminal damages, arson, robbery and shoplifting were requested. This data allows for analysis of the number of crimes in the area, the crime hotspots and helps comparative analysis of crime levels on a yearly basis.

\section{Visual audit of CPTED}

One of the objectives of the research was to explore the interventions, which were introduced in BTC. The visual audit in relation to this research was a visit to the site to observe the current conditions of the CPTED prevention principles. This method was used by other researchers and deemed the most appropriate method in gaining information on the principles used in the town centre, as it placed the research team in the position of a space user to be able to form views on the principles and safety measures whilst using the space.

Surveys

A survey was selected as a research technique to allow the researchers gain data from a large number of respondents. The survey style used for this research was the analytical survey; this was chosen as it allows the researcher to look at the different types of people, their age and how it 
affects their view of crime and the changes made to BTC. The types of questions used for the survey were closed and open questions. Open questions were used towards the end of the survey to allow the participants to express their views once they gained an understanding of the research from previous closed questions. Questions used for the questionnaire were adapted from the official 2015-16 Crime Survey for England and Wales (CSEW). The survey demographic questions asked about ethnicity, gender and age of the participant. It also asked participants if they lived and worked in the area and the length of time they had lived/worked in the area. These questions were asked in order to determine the differences in responses and views to the crime levels and intervention strategies with respect to old and new residents/workers. The next set of questions focused on the safety of the participants. The rest of the survey focused on the different interventions used in the town centre, and participants' thoughts on their quality. The sampling method used for the survey was a convenience sampling method where the researcher approached Brixton residents in the town centre and those who were able to complete the survey did so. Throughout the course of this research a total of 59 surveys were conducted which were all deemed valid. The survey can be found in the supplementary material 1 (online file attachment).

\section{Semi-structured interviews}

The interventions introduced to the town centre did not only affect the users but also the local businesses. In order to gain an insight on how the businesses were affected, the individuals who were willing to participate in short interviews about their experience within the territory of the project were directly approached. The chosen style for the interviews is semi-structured (similar to the surveys) consisted of open and closed questions. This was to allow the interviewer to be more flexible in the questions asked and to gain more in-depth views and opinions. In order to build a rapport with the participant, the interview began with indirect questions. The sampling technique used was also convenience sampling.

\section{Brixton Town Centre}

This research evaluates the effectiveness of the crime prevention approach adopted in the case study of BTC. The site is located in South West London in the Borough of Lambeth and is famous for its large African-Caribbean community. The town centre consists of a lively mixture of enterprises, retails and is iconic for its street markets and has a grade-II listed Town Hall. The town square is formed of three significant independent public spaces, Windrush Square, Tate Gardens and St Matthews's Peace Garden. Windrush Square forms the main central attraction and is next to the local grade-II listed public library and the popular Ritzy Cinema (figure 3).

Brixton is also a busy transportation hub. It holds a number of main roads, bus routes, underground, and overground rail lines. It is a diverse entertainment and shopping area, attracting a multitude of visitors daily. The town centre, however, is known as one of Lambeth's high-crime hotspots, known for having many issues relating to anti-social behaviour, drugs and violence (Dixon 2015). Brixton has been known for its many protests that have led to historic riots involving the police and local residents (Dixon 2015). The Brixton Riots have occurred four times, in 1981, 1985, 1995 and 2011 as part of the London Riots. The town centre has a long-standing drug market. Most of the town's criminal activities has been centrally located.

All of these spaces were redeveloped as a part of the London Mayor's initiative to redevelop 100 spaces in London at the time. The planning of the redevelopment began in 2005 and was completed in 2010 with an objective to create environments where residents could feel safe and at ease. The design was developed by an appointed landscape architect. As part of the CPTED principles, the community was involved in the redesigning of the town and several CPTED elements such as 
improved lighting, CCTV cameras, railings and planting of new trees were introduced. This study focused on how the crime levels changed from 2005 when the intervention process began.

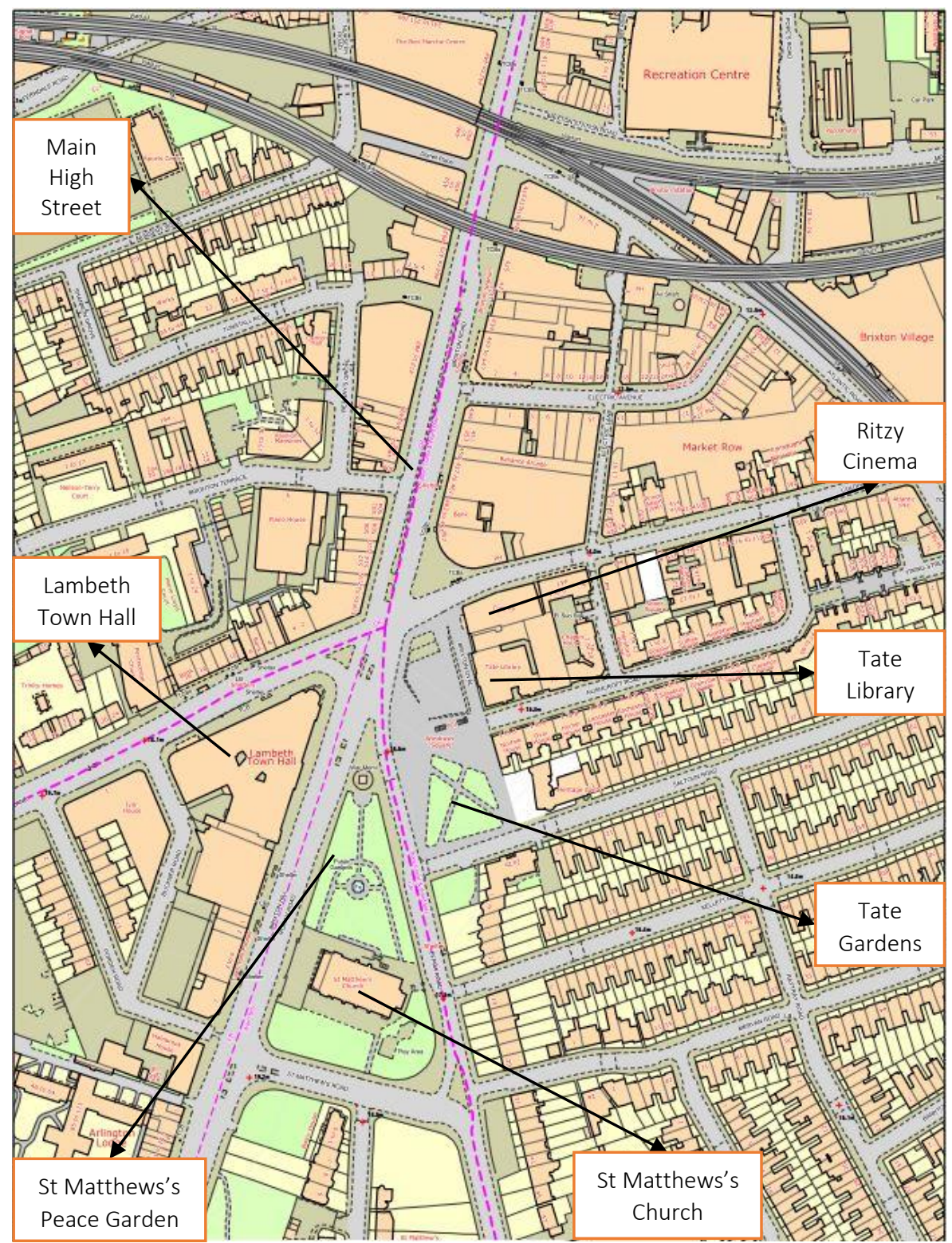

Figure 3 - Brixton Town Centre Layout

\section{Data Collection and Analysis}

\section{Data Collection}

The data collection was carried out in different phases as per the methods and techniques utilized in this research, as follows:

Visual and CPTED Audit took place on one day when the town centre was visited, when elaborated observation of the conditions of the town centre was carried out (figures 4-9).

Using a worksheet with questions regarding the conditions of the town centre, one of five perception scores (1=Bad, $2=$ Poor, $3=$ Fair, $4=$ Good, $5=$ Excellent) were given to each of the questions. Also different CPTED interventions in the area were identified and the status of those CPTED were reviewed in a CPTED audit using a modified version of CPTED audit checklist by Coe (2005); see supplementary material 2 (online file attachment). 
For the semi-structured interviews, participants were required to have knowledge of the town centre pre- and post-interventions, thus a purposive sampling technique was used to identify interviewees. The participants for the interviews included managers, security guards, long-standing employees and police officers on duty.

All stages of this research went through institutional requirements for risk assessment and ethics approvals. In addition, the ethical standards of the Social Research Association were also followed strictly. The researchers conducted research in groups of at least two with suitable backup, emergency contacts and contingency plans in place.

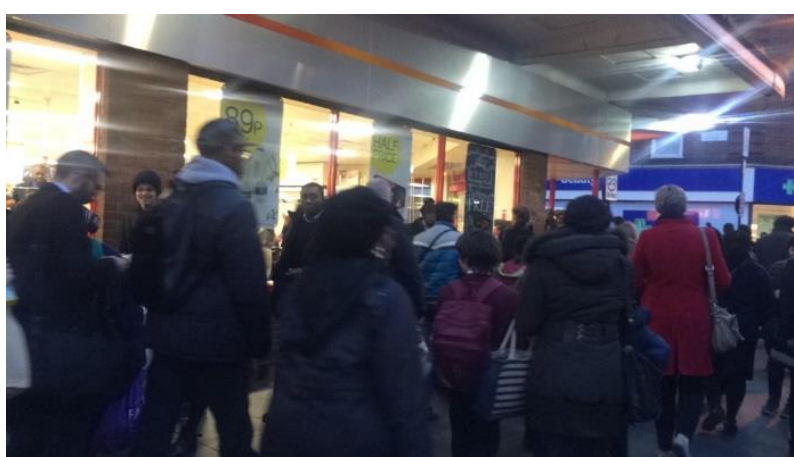

Figure 4-Foot traffic on high street - Morning

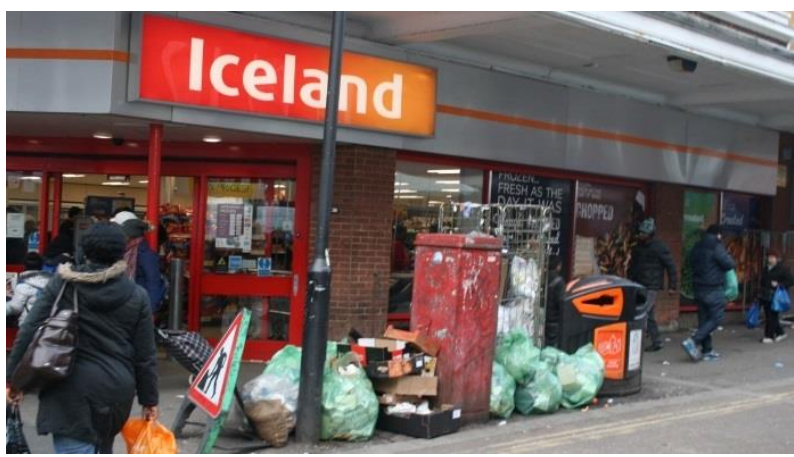

Figure 6- Rubbish left on high street

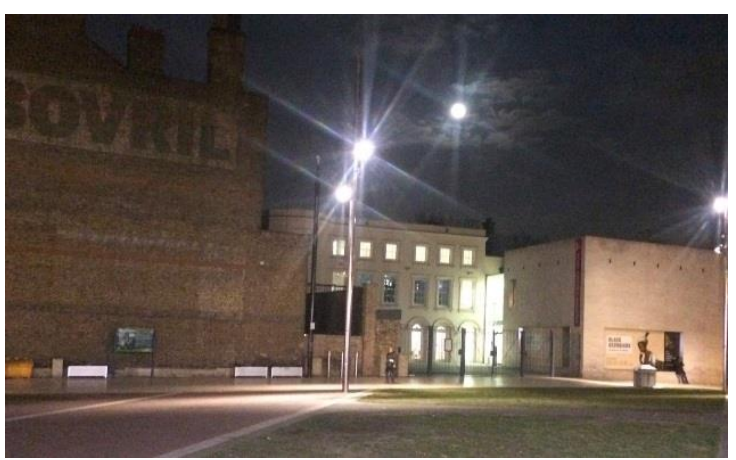

Figure 8- Good lighting Tate park - Evening

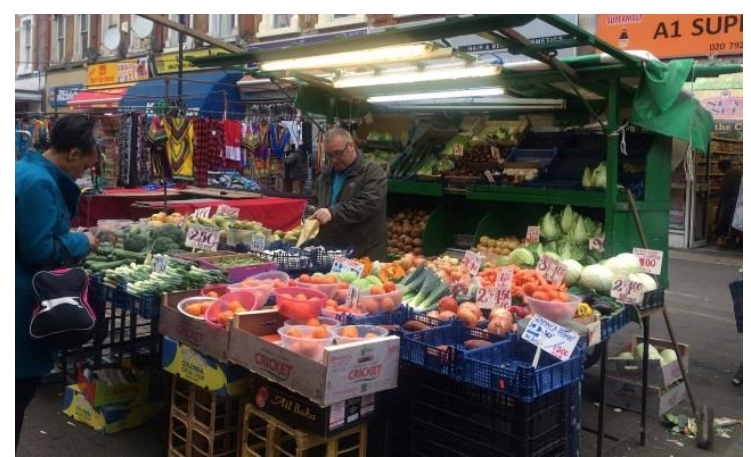

Figure 5- Market stalls on Electric lane

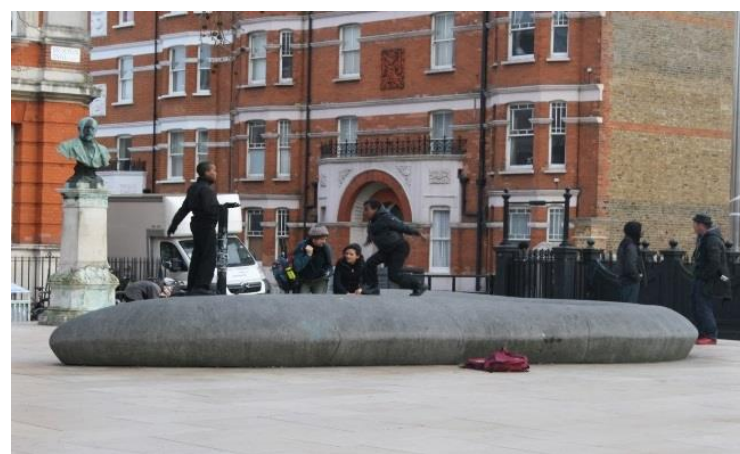

Figure 7- Children using Windrush square

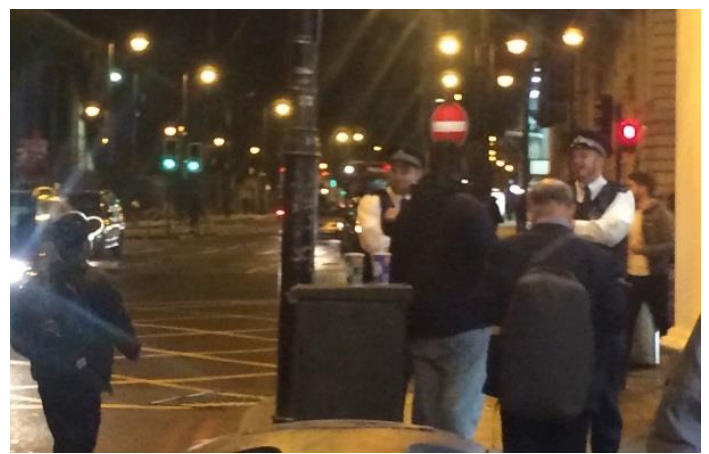

Figure 9- Police presence in town centre

Overview of crime data

A comparative analysis of police recorded crime data was carried out to investigate the crime rates pre- and post-intervention, to establish if there was a significant difference in crime pattern since the interventions were introduced to BTC. Crime data was obtained from the 'Crime and Policing in England, Wales and Northern Ireland' database, which only had the information for Cold Harbour Ward. Comparative analysis of crime levels between 2000 and 2015 can be seen in figure 10. 


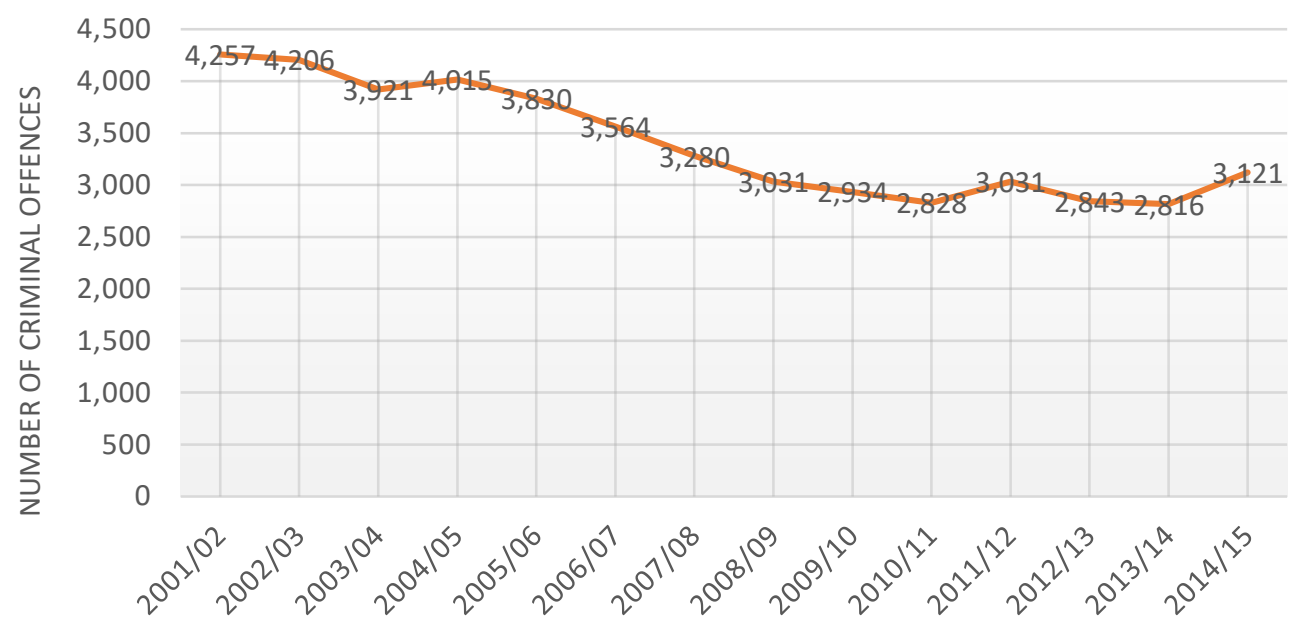

Figure 10 - Police Recorded Crime Data Brixton-Cold Harbour Ward

A comparison between Crime Survey of England and Wales (1981 and 2014) and Police recorded data for Brixton reveals interesting patterns. The general trend for the whole of England and Wales shows a staggered decline similar to that of Brixton. A significant point to note is that after the interventions began in BTC in 2011, there was an increase in the crime rates in England and Wales whilst BTC experienced a decline. From this point on, it can be inferred that there is a slight difference in the crime patterns of the town centre as it follows a slow decline, whilst the rest of England and Wales experienced a staggered decline. It can also be argued that this is due to the changes that were introduced to the town centre.

It was also important to analyse the general crime trend in BTC against neighboring towns in order to assess whether there was a case of displacement and diffusion. Figure 11 shows the crime trends in Clapham Common, Herne Hill and BTC. It is apparent that there had not been significant increases in the crime rates for both of the other areas, therefore, crime displacement did not occur.

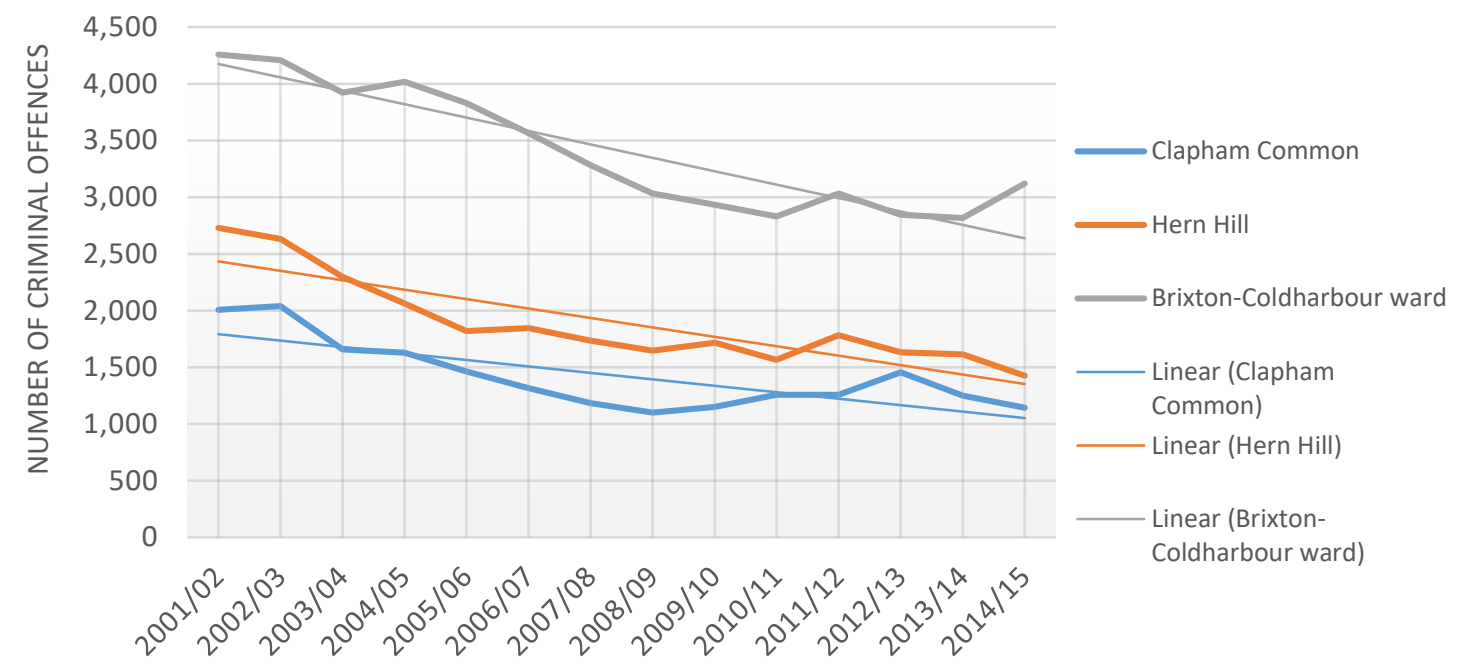

Figure 11 - Crime pattern - Comparison of BTC with Herne Hill and Clapham Common

Weisburd et al. (2006) found that sometimes crime (perpetrators) move to neighboring communities when crime prevention techniques are effective in a given area. The general trend, however, has been a decrease in all of the towns demonstrating that a case of diffusion has occurred. 


\section{Visual audits in light of CPTED interventions}

At the next step, visual audits were carried out for the BTC. Table 2 shows the perception results of the visual audit and the count of each perceived condition:

Table 2 - Perception results of the visual audit and scores of each perceived condition

\begin{tabular}{lcc}
\hline \multicolumn{1}{c}{ Question } & Perception & Score* \\
\hline How comfortable do you feel? & Fair & 4 \\
First impressions of site? & Good & 3 \\
How easy is it to predict pedestrian movement? & Fair & 4 \\
How easy is it to see end of road? & Good & 3 \\
Confined areas for people to hide? & Fair & 4 \\
Routes for criminals to escape? & Fair & 4 \\
Vandalism in the area? & Poor & 2 \\
Graffiti in the area? & Poor & 2 \\
Cleanliness of the area? & Bad & 1 \\
How are users using the space? & Good & 3 \\
\hline * No criteria scored excellent & &
\end{tabular}

Following the visual audits, the CPTED interventions were then identified and assessed. Table 3 indicates the score of CPTED principles for each type of intervention and at different locations where the observation took place. It also provides the total score per location and the total score per intervention. The scores range from 0 to 5 totalling at a maximum of 35 scores per location and also a maximum of 35 scores per intervention, resulting in a possible maximum 245 scores as grand total.

The overall score for all principles in the town centre was 155.5 out of a grand total possible score of 245 . Windrush Square area scored the highest (25.5 out of 35), which could be as a result of the changes made to that area being significant. The overground train station scored the lowest (11 out of 35). This is attributed to insufficient changes to the area, minimal lighting, and the area being closed off to the rest of the town centre. Moreover, as the changes to other areas have been much more successful, the station has become the new spot for alcohol and drug consumption and abuse. Thus, it may seem neglected and out of the main view of many users of the area.

Table 3 - CPTED Principles: Scores at different locations of observation and total scores

\begin{tabular}{|c|c|c|c|c|c|c|c|c|}
\hline \multirow[b]{2}{*}{ CPTED Principle } & \multicolumn{7}{|c|}{ Score } & \multirow[b]{2}{*}{ 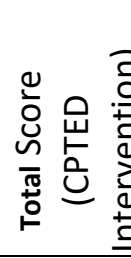 } \\
\hline & 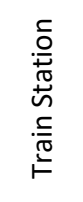 & 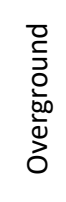 & $\begin{array}{l}\frac{\pi}{d} \\
\frac{1}{4} \\
00 \\
\frac{.}{0} \\
\frac{0}{2} \\
\frac{0}{n}\end{array}$ & 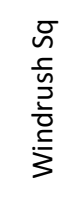 & 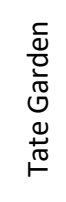 & 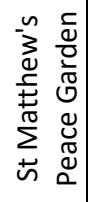 & 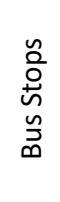 & \\
\hline CCTV & 2 & 2 & 3 & 2.5 & 2 & 2 & 1 & 14.5 \\
\hline Lighting & 4 & 1.5 & 4.5 & 4.5 & 4.5 & 3.5 & 2.5 & 25 \\
\hline Signage & 3.5 & 3 & 4 & 3.5 & 3 & 2 & 4 & 23 \\
\hline Maintenance & 3.5 & 2.5 & 3.5 & 4 & 4 & 4 & 3 & 24.5 \\
\hline Sightlines & 4 & 1 & 3.5 & 5 & 5 & 4 & 4 & 26.5 \\
\hline Territoriality & 3.5 & 0 & 3 & 4 & 4 & 3.5 & 4 & 22 \\
\hline Police presence & 2 & 1 & 4 & 4 & 3.5 & 3 & 2.5 & 20 \\
\hline Total Score (Place) & 22.5 & 11 & 25.5 & 27.5 & 26 & 22 & 21 & 155.5 \\
\hline
\end{tabular}

At next stage a survey was designed to investigate residents' views on the perceived safety and also the CPTED interventions in BTC. 


\section{Survey results and analysis}

Throughout the course of this research a total of 59 surveys were collected. Participants aged 30-40 (39\%) were the most represented while participants aged 50-60 and 18-21 were the least represented with $14 \%$ each. Out of the total survey sample, $39 \%$ of the participants were male and $61 \%$ were female. An overwhelming majority of the participants were of Black or Black British ethnic backgrounds and $5.1 \%$ were of mixed descendants supporting the earlier statistics of the area being predominantly of African-Caribbean residents and users. Lastly, $19 \%$ of the participants had lived or worked in the area for 10 to 20 years, $19 \%$ had also lived and worked in the area for 20 years or more, followed by those who had lived in the area for 5 to 10 years and those for under 12 months (17\% each). Finally, only $5 \%$ had lived and worked in the area for 1-2 years.

When asked how much they thought their lives had been affected by crime in the area, $76 \%$ felt crime had had from 'no impact at all' to 'a neutral effect' in their lives. Similarly $74 \%$ felt very safe or fairly safe walking alone in this area even after the dark. While $82 \%$ of the participants said they had noticed the changes in the town centre, $18 \%$ said they had not. Further analysis showed that the latter notion was mainly associated with new residents who had lived in the area less than 5 years, hence observed no significant change. This was slightly different when the same question was asked about the availability of CCTV in the area. Some $36 \%$ said they had noticed changes in CCTV availability whilst $64 \%$ said they had not. This can be interpreted in two different ways: I) The CCTV coverage is not sufficient in the area, which was noted during the Visual Audit survey, and II) The residents may have also not noticed the CCTV coverage which can be due to lack of proper signage notifying them of CCTV coverage and also positions of the CCTVs or the signage. Thus it can be concluded that the CCTVs would not act as a deterrent to stop crime in this instance as they are not clearly visible. When asked if they had noticed any changes in lighting; there was an even split in opinions as $50 \%$ answered 'no' and the other half answered 'yes'. A majority of the total participants (59\%) rated lighting coverage from medium to very good. Furthermore, $63 \%$ of participants noticed no changing in signage and only $35 \%$ believed that the coverage of signage was medium to very good. Maintenance of the urban spaces showed better results with $74 \%$ believing that there had been changes in maintenance which implies that the appearance of the town centre had improved. Also, $67 \%$ rated the maintenance between average and very good. When asked about the crime rates in the area, $53 \%$ of the participants viewed the crime rates in the area as decreased whilst $7 \%$ said it had increased. However, $40 \%$ believed crime rates had remained the same. According to official police records, crime rates have decreased in the area. Out of the participants that answered 'decreased' to the crime rates, $35 \%$ felt that the changes that had been made to the town centre were a cause for this, $12 \%$ disagreed, whilst another $12 \%$ felt that the decrease was due to other factors. Figure 12 shows the answers to the question "How do you personally feel about the changes made to the town centre?"

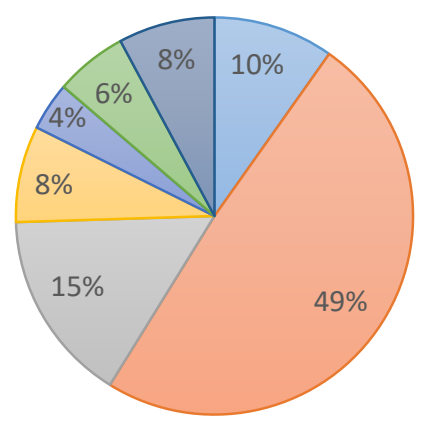

$\square$ Good but more work to be done

$\square$ The changes are great

$\square$ The changes have been good but has caused gentrification $\square$ Not happy with the changes

$\square$ Did not want to comment on the changes

$\square$ Not sure how to feel about the changes

$\square$ I have not noticed the changes

Figure 12 - Public perception on town centre changes 
As indicated in the research methodology and design section, three hypotheses were formulated and their corresponding null hypothesis were tested to gauge people's perception of safety in the BTC. A chi-square test was conducted for gender, age and length of residency against how safe the users feel after dark:

$\mathrm{H}_{1} 1$ : A chi-square test showed that the relationship between gender and how safe people felt in BTC after dark was non-significant $\left[X^{2}(4)=6.535, P>n s\right]$. The Cramer's $V$ test statistic was 0.3 which indicated that the relationship between the two variables was 'weak'. This shows that there is no correlation between gender and safety in BTC. Therefore, the null hypothesis was rejected. This leads to the conclusion that no further specific gender-related changes needed to be implemented.

$\mathrm{H}_{1}$ 2: The chi-square test showed that the relationship between age and how safe people felt in BTC after dark was non-significant $\left[\mathrm{X}^{2}(20)=25.824, \mathrm{P}>\mathrm{ns}\right.$ ] . The Cramer's $\mathrm{V}$ test statistic was 0.6 , which indicated that the relationship between the two variables was 'Moderate'. This shows that there is no correlation between age and safety in BTC. This leads to the conclusion that no specific changes need to be made to target different age groups e.g. making area safer for teenagers, or otherwise for the elderly.

$\mathrm{H}_{1} 3$ : The chi-square test showed that the relationship between length of residency and how safe people felt in BTC after dark was significant $\left[X^{2}(28)=48.809, P<0.05\right]$. The Cramer's V test statistic was 0.891 , which indicated that the relationship between the two variables was 'strong'. This shows that there is a correlation between the length of residency and safety in BTC. The null hypothesis, in this case, is rejected. The hypothesis that residents who had lived in the area over 10 years felt safer was accepted, as $72.7 \%$ of them stated that they felt very safe in the area after dark, which was the highest out of the residency category. This information leads to the conclusion that further improvement to the area will need to include newer residents to ensure that they feel a part of the community and safer whilst using the space.

The next stage was incorporating the complimentary responses from the semi-structured interviews. Audio recordings and field notes were used to collect interview data with the permission of the interviewees. A thematic analysis was then used to code the interview data. They were first transcribed verbatim, then separate interviews were examined, and any recurring statements or patterns found in the participants' answers were highlighted. Proto-themes were created from the initial recurring statements. Taking each of the initial proto-themes, the data was re-examined to find relevant quotes and information. The name of each of the themes was finalized accordingly. Other factors that were not recurring in all the interviews but were considered of significance were categorized into a separate theme. Table 4 below lists the finalized themes.

Table 4 - Key revised themes from interviews

\begin{tabular}{cl}
\hline No. & \multicolumn{1}{c}{ Theme } \\
\hline 1 & Crime that affected business: drugs- and alcohol-related and general theft \\
2 & Initially feared working in Brixton \\
3 & Implemented CCTV, Signage and security as a crime prevention measure \\
4 & Interventions have had a positive effect on criminal activity \\
5 & Changes have created new exciting spaces for the community and tourists \\
6 & Increase of police presence \\
7 & Area still challenging in terms of criminal activity \\
8 & Displacement of criminal activity to other areas in the town \\
\hline
\end{tabular}


Detailed discussion of themes found in the interviews are presented in table 2 in supplementary material 3 (online file attachment).

\section{Discussion of Findings and Concluding Comments}

Environmental criminology examines crime, criminality, and victimization with respect to their relation to particular places. It also investigates the ways in which space users and organizations profile their activities spatially, and how they subsequently are influenced by spatial factors. All five factors ${ }^{5}$ which were deemed necessary and ample by Brantingham and Brantingham (1991) for a crime activity to take place, were present and taken into consideration during the course of this study. Place and time when the crime happens though are the most important constituents of environmental criminology in this study.

The CPTED intervention principles identified in BTC were lighting, signage, maintenance, sightlines, territoriality and, CCTV. Police presence was also recorded as an additional check measure which although may not be directly considered as an independent CPTED measure, it indicates how other measures have been effectively implemented. These intervention principles echo those discussed by Jeffery $(1971)$ and Newman $(1972,1996)$ that should be used to alter an urban environment in order for reduction in crime occurrence. The results from the audits show that these principles have been adopted into BTC efficiently in most areas but some of these principles lack proper maintenance or are in poor condition. This was identified by this research and confirmed by the residents in the questionnaire when asked about their views on the principles.

The idea of signage is to provide information and encourage users to utilize the space and to use it as intended. It also helps differentiate between public and private spaces. Wood (1961) places emphasis on the design of private, semi-private and public spaces, to ensure the design clearly identified the spaces by use of signage. Signage was noted as a principle that needed further improvement in the area.

Lynch (1960) suggested that the physical condition of an area has an effect on the level and fear of crime. Wilson and Kelling's theory (1982) links directly to this principle where it is suggested that if an area is well-kept, it is less likely to attract criminal activity. This was a positive intervention in the area. However, some areas were lacking sufficient maintenance. Maintenance in the area was identified as 'bad' by the research and needed further improvements in specific areas e.g. the overground train station area. The views on maintenance however varied depending on where the user spends most of their time in the town centre. Some areas are maintained very well and others were neglected.

Lighting in the area was a positive factor in the town centre. Lighting is an effective form of surveillance. Perkins et al. (1993) discussed that lighting, especially at night, is a deterrent as the criminal can be seen. It can also reduce the fear of crime which was echoed by Tseloni et al. (2017).

Building upon Jeffery's (1971) suggestion of creating an urban environment where 'normal' users feel safe while 'abnormal' users feel uncomfortable, some residents and users felt safe in the area, but there was still a proportion that felt unsafe which contradicts Jeffery's theory. Due to this factor, the chi-square test was carried out to establish if there was any association between the different ages, length of residency, gender with regard to fear of crime. The null hypothesis could not be rejected for either age or gender, and therefore, there was no correlation between fear of crime and gender or age. However a positive correlation was found between length of residency and fear of

\footnotetext{
${ }^{5}$ Those factors include place, time, offender, target (or victim) and law.
} 
crime. Residents that had lived in the area for a relatively longer period were more comfortable using the space and did not fear walking around at night but newer residents were more fearful. This related back to the 'perception' of BTC by users before using the town centre. Participants were more likely to have a 'fear' of the town centre before using the space frequently and from the results, it can be assumed the same reasons for newer residents feeling 'a little bit unsafe' using the space after dark. The other reason can be that newer residents did not have an experience of the town centre prior to the interventions and their perceptions were based on their more recent exposure to the town centre while the older residents had the advantage of being able to compare the conditions pre- and post-intervention and benefit from a more realistic view about the concept of the safety in the neighborhood. The Interviewees also stated that if they were not regular users of the space, they would be a little bit afraid to come to the town centre. Thus they could empathize with the newer users' fear of the area. Although some users still felt somewhat unsafe, the majority had noticed the changes in the area and highlighted that some of the interventions had contributed to their perception of safety which also contributed to a reduction of criminal activity.

Davies (2004) provides information of different town centres that had experienced a reduction in crime levels due to intervention strategies. The interventions that were used in those towns were also identified in BTC. To assess how the residents and users personally felt about the crime levels and if the changes had an effect on them, they were asked a few questions. The results of the questions asked from the survey showed that $53 \%$ of the users felt that the crime rates had reduced and $35 \%$ of them felt that it was due to the changes that had been made.

The results of the audit and survey have identified the aspects that need improvement in the town centre such as CCTV cameras and signage. The majority of residents, users, business employers and employees of BTC noticed the changes that had been made but stated that further work needed to be done.

From the results of this study, it can be concluded that the crime levels have dropped significantly and continued to decrease since the interventions began which conforms to what Davies (2004) also suggests.

Another interesting observation is from the Concentric Zone Model (CZM) (Park and Burgess 1925, Park and Burgess 1970) point of view, which seeks to explain why certain social groups are located in specific urban areas. BTC has undergone major interventions with an aim to reduce the crime rates which has proven to be relatively successful as was found in this study. Although there is no evidence to suggest that this has instigated gentrification or even caused a major shift in the existing demographic of BTC, the crime rates have diminished, which can suggest that the source of crime either is located outside of Brixton or has moved outside the neighborhood as a result of those interventions being introduced; as suggested by Weisburd et al. (2006). This study however, found that this was not the case and the general trend shows a decrease in all of the neighboring towns which gives rise to the former assumption that is: the source of crime in BTC has been located outside the neighborhood. Assuming that this conclusion is plausible, together with CZM, it also challenges the Social Disorganization Theory (as a part of ecological theories suite), which suggests that individuals' location of residence is a substantial determinant affecting the likelihood of those individuals getting involved in crime or unlawful activities ${ }^{6}$.

\footnotetext{
${ }^{6}$ This however, is not new as some scholars believe that Social Disorganization Theory has already started losing the ground to psychological theories of crime since early 1970s, while others have started attempts to reinstate it in early 2000s (see for instance: Kubrin, C. E. and R. Weitzer (2003). "New directions in social disorganization theory." Journal of research in crime and deliquency 40(4): 372-402.)
} 
Although the interventions have led to the overall decrease in crime levels, there is still more which can be done to maintain the crime levels relatively low and to ideally lower them further.

Understandably, CPTED cannot tackle all criminal activities. The police stated they were on high patrol in the area while the research was being carried out due to youth gangs and a recent shooting in the area. This could have had skewed the results.

A theme that emerged throughout the study was that 'more work needs to be done'. This was stated by many residents as well as the police. Another theory which arose was that the users of BTC may have lost the sense of ownership and territoriality of the area. In essence, it is 'everyone needs to look after themselves and not worry about anyone else'. This theory was confirmed by some direct comments received during the interviews:

'If you keep yourself to yourself, you will be safe in the town centre, just don't get involved or look when something is happening'

'I just don't get involved in anything, I just turn a blind eye and keep going. If I don't bother anyone, they won't bother me'

This was not a general theme across the interviews but it was certainly a theme that emerged. This shows that the collective efficacy, as an alternative to broken windows theory, may have not been effectively at work in BTC. It therefore, suggests that because the residents and business owners do not work to prevent small crimes, a sense of disorder may develop in the town center. This in turn reproduces fear in the minds of residents and other space users, who may come to the conclusion that the neighborhood is unsafe and thus withdraw from the community. This will presumably weaken the social controls that previously kept criminals in check. This process reciprocates itself, meaning that disorder causes crime, and crime in turn creates more fear and leads to an elevated level of disorder.

The above is however not the only theoretical inference which could be made. The study also led to an unprecedented theory that at the point where there is a change from the negative correlation to a positive correlation; users and residents lose the sense of ownership and territoriality; whose roots and reasons are yet to be investigated in more details. In other words, semi-public spaces are regarded as public spaces by users. Jane Jacobs's theory of "Eyes on the Street" connects to this theory. But it is also possible that this theory is less effective in a busy environment where users focus on their task at hand or simply want to keep to themselves.

Apart from the general limitations associated with CPTED, mainly due to its complexity and exclusivity (Cozens and Love 2015), CPTED is susceptible to a reluctance of planning authorities to engage in crime prevention from very early stages in urban projects. Moreover, similar to any other collaborative initiatives, it is also highly dependent on effective communication and collaboration between the stakeholders. Although this has not affected the current study due to high response rate and willingness of the locals to participate, the impact of the demographics of the participants should not be underestimated. The fact that such initiatives in the UK are traditionally mostly topdown, the findings of this research suggests that a feedback loop to facilitate the learning process from post-occupancy (in-use) stages of urban spaces can be beneficial to inform new projects with respect to CPTED and other spatial or place-based crime prevention measures. Furthermore, introducing a new bottom-up community-based collaborative mechanism integrated in planning process can help improve participation of different space user groups and facilitate their role in proactive participation in crime prevention in their neighborhoods. Building up a nationwide database to document CPTED (as well as other placed-based crime prevention) measures, their 
effectiveness, impacts, as well as direct and indirect costs and benefits associated with them can help provide hard evidence for designers, local authorities and the UK government to take a more proactive preventive stance to tackle urban crime. This can help create a life cycle profile of urban spaces throughout the country and further develop a simulation model to predict crime cycles and the surge in antisocial or unlawful behavior in urban spaces. This can be linked with the concept of Smart Cities and help drive this initiative forward faster and in a more meaningful manner.

This study laid the foundations for further investigation into why the intervention measures do not seem to have been fully functional. Future studies are required to quantitatively measure how those interventions may have affected the safety of the urban space and whether or not they can be explained using other alternative methods such as the Space Syntax analysis method. And finally if there are any discrepancies in events, where are they rooted, and whether we are in need of another theory to be able to appropriately explain the pattern emerging in the context of this study. Such a theory can be in the form of a new conjunctural theory which would seek to refine or upgrade the existing theories in place-based crime prevention by highlighting the shortcoming of exiting mainstream psychological theories of crime in urban spaces and thus proposing a new outlook - perhaps with few new dimensions or perspectives - which can be customized to best suit the context-specifics of the urban space where the crime prevention measures are to be or have been introduced.

\section{Acknowledgements}

The authors wish to thank Magdalene Osei-Berchie and Anita Dosanjh who kindly helped with the data collection during the field study, surveys and interviews; the Brixton Hill Police, Metropolitan Police Services for their close cooperation, University of Brighton for providing ethical, health and safety guidance and the Lambeth and Brixton local communities, local businesses and local space users who offered their time, participated in this study, and individually, socially and morally supported it.

\section{References}

Amiri, S., Brooks, K.R., Vila, B.J. and Daratha, K.B., (2019). "Natural surveillance characteristics of building openings and relationship to residential burglary". Applied Geography, 102: 99-108.

Allen, M. R. and N. Wendl (2014). "After Pruitt-Igoe: An Urban Forest as an Evolving Temporal Landscape." Studies in the History of Gardens and Designed Landscapes 34(1): 101-112.

Bernard, T. J. (1984). "Control Criticisms of Strain Theories: An Assessment of Theoretical and Empirical Adequacy." Journal of Research in Crime and Delinquency 21(4): 353-372.

Brantingham, P. J. E. and P. L. E. Brantingham (1991). Environmental criminology, Waveland Press. Cloward, R. A. and L. E. Ohlin (1960). Delinquency and Opportunity: A Theory of Delinquent Gangs. New York Free Press.

Coe, M. (2005). CPTED Audit \& Site Assessment Checklists.

Cohen, A. K. (1955). Delinquent Boys: The Culture of the Gang. Glencoe, IL, Free Press.

Cornish, D. and R. Clarke (1986). The reasoning criminal : Rational choice perspectives on offending. New York, Springer-Verlag

Cornish, D. B. and R. V. Clarke (2002). Analyzing Organized Crimes. Rational Choice and Criminal Behavior: Recent Research and Future Challenges. A. R. Piquero and S. G. Tibbetts. New York, Garland: 41-62.

Cozens, P. (2008). Crime prevention through environmental design. Environmental criminology and crime analysis. R. Wortley and L. Mazerolle. Portlan, Oregon, USA, Willan publishing. Cozens, P. and T. Love (2015). "A Review and Current Status of Crime Prevention through Environmental Design (CPTED)." Journal of Planning Literature 30(4): 393-412. 
Crawford, A. and K. Evans (2017). Crime Prevention and Community Safety. The Oxford Handbook of Criminology. A. Liebling, S. Maruna and L. McAra. Oxford, Oxford University Press: 797-824.

Currie, E. (1985). Confronting Crime: An American Challenge. New York, Pantheon Books.

Davies, L. (2004). Safer Places: the Planning System and Crime Prevention. London, England, Office of the Deputy Prime Minister.

Dixon, B. (2015). "Making further inquiries: Policing in context in Brixton and Khayelitsha." South

African Crime Quarterly 53: 5-14.

Dorn, M. S. (2005). Safety by Design. . College Planning and Management Springboro, OH, 1105

Media, Inc. . 2005.

Farr, E. R. P. and P. Piroozfar (2013). Cities for all: all-inclusive collective urban spaces for the public a case of a successful interactive model. 18th International Conference on Urban Planning, Regional Development and Information Society, Vienna, Schwechat-Rannersdorf.

Fink, A. E. (1938). Causes of Crime: Biological Theories in the United States 1800-1915 Philadelphia, University of Pennsylvania Press.

Garofalo, J. (1981). "The fear of crime: Causes and consequences." The journal of criminal law and criminology 72(2): 839-857.

Harcourt, B. E. (2001). Illusion of Order: The False Promise of Broken Windows Policing Cambridge and London, Harvard University Press.

Hirschi, T. (1969). Causes of Delinquency. Berkeley, University of California Press.

Jacobs, J. (1961). The Death and Life of Great American Cities. New York, Random House.

Jeffery, C. R. (1971). Crime Prevention Through Environmental Design. Beverly Hills, CA, Sage

Publications.

Jeffery, C. R. and D. L. Zahm (1993). Crime prevention through environmental design, opportunity theory, and rational choice models. Routine activity and rational choice: Vol. 5. Advances in

criminological theory. R. V. Clarke and M. Felson. New Brunswick, NJ, Transaction Publishers: 323350.

Kelling, G. L. and J. Q. Wilson (1982). Broken Windows: The police and neighborhood safety. The Atlantic. Washigton D.C. March Issue.

Knoblauch, J. (2015). "The Economy of Fear: Oscar Newman Launches Crime Prevention through Urban Design (1969-197x)." Architectural Theory Review 19(3): 336-354.

Kornhauser, R. (1978). Social sources of delinquency: an appraisal of analytic models. Chicago, University of Chicago Press.

Kubrin, C. E. and R. Weitzer (2003). "New directions in social disorganization theory." Journal of research in crime and deliquency 40(4): 372-402.

Lea, J. and J. Young (1984). What is to be Done about Law and Order? Crisis in the Eighties.

Harmondsworth, UK, Penguin.

Lynch, K. (1960). The image of the city. Cambridge Mass., Technology Press.

Merton, R. K. (1957). Social Theory and Social Structure. New York, Free Press.

Moore, D. P. (2000). Safe and Secure Schools. School Planning and Management. Springboro, OH, 1105 Media, Inc. . 2000.

Newman, O. (1972). Defensible space; crime prevention through urban design. New York,, Macmillan.

Newman, O. (1996). Creating defensible space. Washington, D.C., Rutgers University, Center for Urban Policy Research, and U.S. Dept. of Housing and Urban Development, Office of Policy Development and Research.

Park, R. E. and E. W. Burgess (1925). The city. Chicago, University of Chicago Press.

Park, R. E. and E. W. Burgess (1970). Introduction to the science of sociology. Chicago ; London, University of Chicago Press.

Parnaby, P. F. (2006). "Crime Prevention Through Environmental Design: Discourses of Risk, Social Control, and a Neo-Liberal Context." Canadian Journal of Criminology and Criminal Justice 48(1): 129. 
Perkins, D. D., A. Wandersman, R. C. Rich and R. B. Taylor (1993). "The physical environment of street crime: Defensible space, territoriality and incivilities." Journal of Environmental Psychology 13(1): 29-49.

Roberts, D. (1999). "Foreword: Race, Vagueness, and the Social Meaning of Order-Maintenance Policing." The Journal of Criminal Law and Criminology 89(3): 775-836.

Robinson, M. B. (1996). The Theoretical Development of 'CPTED': 25 Years of Responses to C. Ray Jeffery. Advances in Criminological Theory, Vol. 8. . W. Laufer and F. Adler. New Jersey, Transaction Publishers.

Sampson, R. and S. Raudenbush (2004). "Seeing Disorder: Neighborhood Stigma and the Social Construction of "Broken Windows"." Social Psychology Quarterly 67(4): 319-342.

Saville, G. and G. Cleveland (1997). 2nd Generation CPTED: An Antidote to the Social Y2K Virus of Urban Design. 2nd Annual International CPTED Conference Orlando, Florida.

Schneider, R. H. and T. Kitchen (2002). Planning for Crime Prevention: A Transatlantic Perspective. London and New York, Routledge.

School of Education (2016). Theories and causes of crime, The Scottish Centre of Crime and Justice Research, School of Education, University of Glasgow.

Shaw, C. R. and H. D. McKay (1942). Juvenile delinquency and urban areas; A study of rates of delinquents in relation to differential characteristics of local communities in American cities.

Chicago, University of Chicago Press.

Shjarback, J. A. (2014). Defensible Space Theory. The Encyclopedia of Theoretical Criminology. J. M. Miller. Chichester, UK, John Wiley \& Sons.

Siegel, L. J. (2011). Criminology: the core. Belmont, CA, Wadsworth/Cengage Learning.

Siegel, L. J. (2016). Criminology: theories, patterns, and typologies. Belmont, CA, Wadsworth

Cengage Learning.

Taylor, R. B. (2001). Breaking away from broken windows: Baltimore neighborhoods and the nationwide fight against crime, grime, fear, and decline. Boulder, $\mathrm{CO}$; Oxford, Westview Press. Thacher, D. (2004). "Order Maintenance Reconsidered: Moving beyond Strong Causal Reasoning." Journal of Criminal Law and Criminology.94(2): 381-414.

Tseloni, A., R. Thompson, L. Grove, N. Tilley and G. Farrell (2017). "The effectiveness of burglary security devices." Security Journal 30(2): 646-664.

Weisburd, D. L., L. Wyckoff, J. Ready, J. E. Eck, J. Hinkle and F. Gajewski (2006). "Does crime just move around the corner? A controlled study of spatial displacement and diffusion of crime control benefits." Criminology 44: 549-592.

Wood, E. (1961). Housing Design: A Social Theory. New York Citizens' Housing and Planning Council of New York.

Yin, R. K. (2014). Case study research : design and methods. Los Angeles, SAGE. 